\title{
Chemical and Biological Properties of Hot Water Extract from Delipidated Cells of Mycobacterium bovis Strain BCG
}

\author{
Hirosi Sato, Atsunobu Yokosawa, Hideo Arai, Hiromi \\ Nagai, Kenkichi Kurita, Nobuko Kumano, Masakichi \\ Motomiya and Kiyoshi Konno \\ The Research Institute for Tuberculosis, Leprosy and Cancer, \\ Tohoku University, Sendai
}

\begin{abstract}
Sato, H., Yokosawa, A., Arat, H., Nagai, H., Kurita, K., Kumano, N., Mотомту, M. and Konno, K. Chemical and Biological Properties of Hot Water Extract from Delipidated Cells of Mycobacterium boris Strain BCG. Tohoku J. exp. Med., 1976, 120 (1), 75-81 — A water-soluble fraction was isolated from delipidated cells of Mycobacterium bovis strain BCG by extraction with hot water. Chemical analyses revealed that the above fraction presumably consisted of a peptidoglycan containing $5-10 \%$ of nucleic acids. When it was injected into guinea pigs with Freund's incomplete adjuvant plus egg white albumin as antigen, an increase of circulating antibody was observed as shown by the augmented titers of precipitin and hemagglutinin. The results of skin test and corneal reaction indicated that the fraction mentioned above induced delayed hypersensitivity to egg white albumin. Footpad reaction in mice demonstrated that the above fraction induced delayed hypersensitivity to sheep red blood cells. It was confirmed in addition that the adjuvant activity of this fraction was not due to the presence of nucleic acids. This adjuvant-active fraction was designated as HSA (hotwater soluble adjuvant). —— extract from $\mathrm{BCG}$; adjuvant activity
\end{abstract}

Freund and McDermott (1942) demonstrated that an injection of killed mycobacteria with an antigen emulsified in mineral oil increased the titer of circulating antibody and caused delayed hypersensitivity against the antigen. Since then, water-in-oil emulsion containing mycobacteria has been used as potent adjuvant. Raffel and Cal (1950) ascribed the adjuvant activity of mycobacteria to $\operatorname{wax} \mathrm{D}$. The wax $\mathrm{D}$, a fraction insoluble in hot acetone of the chloroform extract from mycobacteria, is a peptidoglycolipid and is known to be the main component of the cell wall of mycobacteria.

Recently, water-soluble substances which are adjuvant-active have been isolated from delipidated mycobacteria and from cell wall by means of hydrogenation (Hiu 1972), enzymatic treatment (Adam et al. 1972, 1973) and ultrasonication (MiglioreSamour and Jollès 1972, 1973). This report deals with the isolation of a watersoluble fraction from delipidated Mycobacterium bovis strain BCG by extraction with hot water. The fraction thus prepared was found to be adjuvant-active as revealed by the results of the tests for biological activities in guinea pigs.

Received for publication, April 28, 1976. 
This fraction, hereafter referred to as HSA (hot-water soluble adjuvant), may be useful as adjuvant in place of whole cells of mycobacteria. The differences in chemical composition of HSA from that of other water-soluble adjuvants was also discussed.

\section{Materials and Methods}

\section{Preparation of HSA}

Mycobacterium bovis strain BCG (Japanese strain, Tokyo No. 172, supplied by National Institute of Health, Tokyo, Japan), subcultured for 4 weeks on a modified Sauton medium (Sato et al. 1969) was filtered and washed with distilled water. It was delipidated with a 1:1 mixture of ether and ethanol, chloroform and then with a 2:1 mixture of chloroform and methanol. The defatted bacilli were pulverized in a mortar, then washed thoroughly with 3 changes of water at room temperature. The bacillary suspension in water was heated at $100^{\circ} \mathrm{C}$ for $15 \mathrm{~min}$, passed through a sheet of filter paper, and then through a Millipore Filter $(0.45 \mu \mathrm{m})$ (Millipore Filter Corporation, Massachusetts, U.S.A.) for the removal of cell debris and was concentrated in vacuo. The precipitate prepared by the addition of 3 volumes of acetone to the above concentrate was separated by centrifugation. The resulting supernatant was concentrated and then was mixed with 3 volumes of acetone. The precipitate thus obtained was dialyzed against distilled water for $48 \mathrm{hr}$ and the retentate was lyophilized.

\section{Analytical methods}

Neutral sugars were identified by paper chromatography on Toyoroshi filter paper No. 51 in the solvent systems of ethyl acetate-acetic acid-formic acid-water $(90: 15: 5: 20)$ and n-butanol-pyridine-water $(6: 4: 3)$, respectively. Quantitative determination of hexose was made by Roe's method (1955) and by phenol-sulfuric acid reagent. In gas-liquidchromatographic analysis of neutral sugars, a use was made of a column of $3 \%$ ECNSS-M on Gaschrom Q. Amino sugars were identified after hydrolysis for $4 \mathrm{hr}$ at $110^{\circ} \mathrm{C}$ in $4 \mathrm{~N} \mathrm{HCl}$ by paper chromatography in the solvent systems of ethyl acetate-pyridine-n-butanol-butyrio acid-water (10:10:5:1:5) and ethyl acetate-pyridine-water-acetic acid (5:5:1:3). Quantitative estimation of amino sugar was carried out by the method of Elson-Morgan modified by Blix (1948). A column of $15 \%$ Apiezon M on Chromosorb CLH was employed in gasliquid-chromatographic analysis of amino sugars. Amino acids were analyzed also by an amino acid autoanalyzer, JLC-5AH. Ninhydrin-positive substance was measured as described by Yemm and Cocking (1955). For the detection of nucleic acid, absorbance in an aqueous solution was recorded from $260 \mathrm{~nm}$ to $320 \mathrm{~nm}$. Quantification of nucleic acid was carried out as described by Schmidt and Thannhauser (1945), and by Schneider (1946).

In the next experiment HSA was applied on a $2.5 \times 60 \mathrm{~cm}$ column of Sephadex-G 75 and was eluted with $0.1 \mathrm{~N}$ acetic acid. An aliquot from $4 \mathrm{ml}$-portions in each tube was monitored by quantitative determination of neutral sugar and ninhydrin-positive substance. As illustrated in Fig. I, there were two separate peaks. The second peak, referred to as Fr-II, was analyzed by chemical and biological methods in a similar manner as HSA.

\section{Biological activity}

Male albino guinea pigs weighing $250-300 \mathrm{~g}$ were sensitized by an injection of $0.1 \mathrm{ml}$ of water-in-oil emulsion made of an equal part each of Freund's incomplete adjuvant and the saline containing $2 \mathrm{mg}$ of egg white albumin plus $0.2 \mathrm{mg}$ of HSA, or BCG cells. On the 21 st day after sensitization, $0.1 \mathrm{mg}$ and $0.01 \mathrm{mg}$ respectively of egg white albumin in $0.1 \mathrm{ml}$ of saline were injected intradermally at different sites of the back. The corneal test according to Stewart-Tull's method (Stewart-Tull and White 1967) was done on the same day. The diameter of induration and the turbidity of the cornea were measured at 24 th and 48 th hr. Four weeks after sensitization blood was taken by heart puncture 
for the quantitative determination of the precipitin titer (Kabat and Mayer 1961) and for passive hemagglutination test (Middlebrook and Dubos 1948).

Male ddI mice received an intraperitoneal or intradermal injection of HSA, Fr-II and BCG respectively 12 or 4 days before sensitization. As sensitizing antigen $10^{8}$ sheep red blood cells (SRBC) were injected intraperitoneally. After 4 days, $10^{8}$ SRBC were injected intradermally on the right hind footpad and the thickness was compared with that of the non-injected footpad after $24 \mathrm{hr}$.

\section{Results}

Physical and chemical properties

From $50 \mathrm{~g}$ of the dry delipidated BCG approximately $1.5 \mathrm{~g}(3 \%)$ of HSA was obtained. HSA, when lyophilized, was a whitish powder. It was easily soluble in water and the resulting aqueous solution was slightly opalescent.

The result of fractionation by a column of Sephadex-G 75, as illustrated in Fig. 1, showed two separate peaks. In the aqueous solution, an absorption maximum was observed at $260 \mathrm{~nm}$, but none at $280 \mathrm{~nm}$. The quantitative data showed that the HSA consisted of $50-60 \%$ of neutral sugar, $1-3 \%$ of amino sugar, $15-20 \%$ of ninhydrin-positive substance and $5-10 \%$ of nucleic acid.

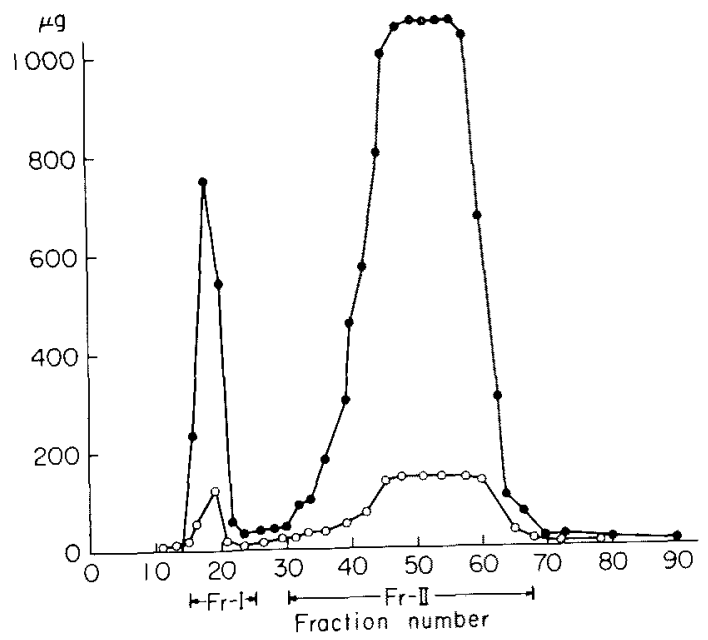

Fig. 1. Elution pattern of $400 \mathrm{mg}$ of HSA from a $2.5 \times 60 \mathrm{~cm}$ column of SephadexG 75. Elution was effected with $0.1 \mathrm{~N}$ acetie acid. Fractions $(4 \mathrm{ml})$ were analyzed for neutral sugar by phenol-sulfuric acid reagent and for ninhydrin-positive substance by the method of Yemm and Cocking (calculated as alanine). - neutral sugar; o-o, ninhydrin-positive substance.

Fr-II was found to contain $60-70 \%$ of neutral sugar, $2-3 \%$ of amino sugar, $15-20 \%$ of ninhydrin-positive substance and less than $1 \%$ of nucleic acid.

Paper-chromatography and gas-liquid-chromatography revealed the presence of ribose, arabinose, galactose, mannose and glucose. The quantity of the latter 
two sugars, which were the main components of neutral sugars, constituted $90 \%$ of the total quantity of neutral sugars in HSA as well as in Fr-II.

On paper-chromatograns of amino sugars, glucosamine and muramic acid were detected. As shown in Table 1, not only Ala, Glu and diaminopimelic acid, but some other amino acids were also detected.

TABLE 1. Amino acid constituents

\begin{tabular}{|c|c|c|c|c|c|}
\hline \multirow{2}{*}{ Amino acid } & \multicolumn{2}{|c|}{ Molar ratio } & \multirow{2}{*}{ Amino acid } & \multicolumn{2}{|c|}{ Molar ratio } \\
\hline & HSA & Fr-II & & HSA & Fr-II \\
\hline Asp & 43.1 & 97.0 & Met & 0 & 0 \\
\hline Thr & 25.6 & 43,2 & DAP & 1.0 & 1.0 \\
\hline Ser & 20.2 & 41.7 & Ile & 15.9 & 16.8 \\
\hline Glu & 53.6 & 162.5 & Leu & 32.2 & 38.8 \\
\hline Pro & 35.2 & 58.2 & Tyr & 3.2 & 5.2 \\
\hline Gly & 62.6 & 142.0 & Phe & 8.9 & 8.8 \\
\hline Ala & 55.7 & 98.8 & Lys & 22.1 & 100.7 \\
\hline Cys & 0 & 0 & His & 5.2 & 9.2 \\
\hline Val & 31.6 & 42.8 & Arg & 21.0 & 45.5 \\
\hline
\end{tabular}

DAP : diaminopimelic acid.

\section{Biological activity}

Table 2 summarizes the results of experiments on humoral antibody response to egg white albumin. In the guinea pigs sensitized with Freund's incomplete adjuvant containing $\mathrm{HSA}$, the titer of precipitin and that of hemagglutinin were significantly augmented $(p<0.001)$. As shown in Table 3 , the results of skin test and corneal reaction 3 weeks after sensitization were positive in the animals which had received either HSA or Fr-II in Freund's incomplete adjuvant.

Table 4 summarizes the results of the footpad reaction. An increase in thickness of footpad was found also in the mice which had been injected with HSA and Fr-II.

TABLE 2. Humoral antibody response to egg white albumin

\begin{tabular}{clrr} 
Number of aminals & Injected with & $\begin{array}{r}\mu \mathrm{g} \mathrm{N} / \mathrm{ml} \text { serum* } \\
\text { mean } \pm \mathrm{S.D.}\end{array}$ & $\begin{array}{c}\text { PHA } \\
\text { mean } \pm \text { s.D. }\end{array}$ \\
\hline 5 & Saline & $28 \pm 17$ & $4 \pm 0$ \\
5 & FIA & $283 \pm 157$ & $282 \pm 140$ \\
10 & FIA + HSA & $722 \pm 208$ & $1024 \pm 591$ \\
10 & FIA + Fr-II & $339 \pm 163$ & $486 \pm 244$ \\
5 & FIA + BCG & $1642 \pm 541$ & $2253 \pm 1122$ \\
\hline
\end{tabular}

* Determined by quantitative precipitation test.

PHA: passive hemagglutin, reciprocal titer.

FIA: Freund's incomplete adjuvant (Difco). 
TABLE 3. Delayed hypersensitivity to egg white albumin

\begin{tabular}{clccccc}
\hline \multirow{2}{*}{ Number of animals } & Injected with & $\begin{array}{c}\text { Skin test } \\
\text { positive }\end{array}$ & \multicolumn{3}{c}{ Corneal reaction } \\
\hline 5 & Saline & $0 / 5$ & 5 & & & \\
5 & FIA & $0 / 5$ & 5 & & & \\
10 & FIA + HSA & $9 / 10$ & 5 & 2 & 1 & 1 \\
10 & FIA + Fr-II & $8 / 10$ & 4 & 3 & 1 & 2 \\
5 & FIA + BCG & $5 / 5$ & & 3 & 2 & \\
\hline
\end{tabular}

- : absent-turbidity, + : slight-turbidity, $\#$ : moderate-turbidity, H: markedturbidity with chemosis

TABLE 4. Footpad reaction

\begin{tabular}{ccccc}
\hline Number of mice & Injected with & Route & Day & Increase in footpad thickness $\overline{10^{-1} \mathrm{~mm}}$ \\
\hline 20 & Saline & i.p. & -4 & $1.14 \pm 0.69$ \\
10 & HSA & i.p. & -4 & $\mathbf{2 . 3 4} \pm 0.90$ \\
10 & HSA & i.d. & -4 & $1.71 \pm 0.89$ \\
10 & HSA & i.d. & -12 & $3.00 \pm 0.90$ \\
10 & Fr-II & i.d. & -4 & $3.61 \pm 1.18$ \\
10 & Fr-II & i.d. & -4 & $\mathbf{2 . 2 7} \pm 1.10$ \\
10 & Fr-II & i.d. & -12 & $2.73 \pm 1.04$ \\
10 & BCG & i.p. & -4 & $5.60 \pm 2.01$ \\
10 & BCG & i.d. & $-\mathbf{1 2}$ & $3.01 \pm \mathbf{1 . 1 6}$ \\
\hline
\end{tabular}

Sensitizing dose: $10^{8}$ SRBC i.p. Eliciting dose: $10^{8}$ SRBC.

i.p., intraperitoneal; i.d., intradermal. -4 , injection 4 days before sensitization; -12 , injection 12 days before sensitization.

\section{Discussion}

Not only live or killed mycobacteria, but also mycobacterial preparations such as cell wall (Lederer 1971) and methanol extracted residue (Shlomo et al. 1973) have been reported to be adjuvant-active. In addition, adjuvant activity of several water-soluble substances from delipidated mycobacteria has been reported. In the present study, a hot water extract from delipidated BCG cell was adjuvant-active and was designated as HSA (hot-water soluble adjuvant). However, the chemical composition of HSA was somewhat different from that of other water-soluble adjuvants.

In the present investigation the presence of ribose was confirmed by paperchromatography and by gas-liquid-chromatography. There was an absorption maximum at $260 \mathrm{~nm}$. Thus the presence of nucleic acid in HSA was suggested. Other water-soluble adjuvants so far reported contain no nucleic acid. On the other hand, Casavant and Youmans (1975) found that $0.2 \mathrm{mg}$ of mycobacterial RNA injected together with Freund's incomplete adjuvant was adjuvant-active in guinea pigs.

There was a possibility that the adjuvant activity of HSA was due to the presence of nucleic acid. However, judging from the content of nucleic acid in Fr-II (less than 1\%), it is unlikely that the adjuvant activity of HSA is due to 
nucleic acid. In the water-soluble adjuvant described by Hiu (1972) and Adam et al. (1972), the main component of neutral sugars was arabinose and galactose. Thus they thought that arabinogalactan from cell wall was extracted. In the case of HSA only traces of arabinose and galactose were detected. Mannose and glucose were the main components of neutral sugars when evaluated by gas-liquidchromatography. In addition, the difference in composition of neutral sugars and the very low content of DAP (diaminopimelic acid) suggested that a substance other than arabinogalactan-mucopeptide from cell wall is responsible for adjuvant activity of HSA.

The content of amino sugar was not more than $3 \%$ after hydrolysis under various conditions.

Chedid et al. (1972) investigated the biological activity of the water-soluble adjuvant prepared by Adam and found no toxic effect inherent to whole cells, when it was administered with saline. The biological activities other than adjuvant effect of HSA are now under investigation.

\section{References}

1) Adam, A., Ciorbaru, R. Petit, J.F. \& Lederer, E. (1972) Isolation and properties of a macromolecular, water-soluble, immunoadjuvant fraction from the cell wall of Mycobacterium smegmatis. Proc. nat. Acad. Sci, USA, 69, 851-854.

2) Adam, A., Ciorbaru, R., Pepit, J.F., Lederer, E., Chedid, L., Lamensans, A., Parant, F., Parant, M., Rosselet, J.F. \& Berger, F.M. (1973) Preparation and biological properties of water-soluble adjuvant fractions from delipidated cells of Mycobacterium smegmatis and Nocardia opaca. Infect. Immun., 7, 855-861.

3) Blix, G. (1948) The determination of hexosamines according to Elson and Morgan. Acta chem. scand., 2, 467-473.

4) Casavant, C.H. \& Youmans, G.P. (1975) The adjuvant activity of mycobacterial RNA preparations and synthetic polynucleotides for induction of delayed hypersensitivity to purified protein derivative in guinea pigs. J. Immunol., 114, 1014-1022.

5) Chedid, L., Parant, M., Parant, F., Gustafson, R.H. \& Berger, F.M. (1972) Biological study of a nontoxic, water-soluble immunoadjuvant from mycobacterial cell walls. Proc. nat. Acad. Sci. USA, 69, 855-858.

6) Freund, J. \& McDermott, K. (1942) Sensitization to horse serum by means of adjuvants. Proc. Soc. exp. Biol. Med. (N.Y.), 49, 548-551.

7) Hiu, L.J. (1972) Water-soluble and lipid free fraction from BCG with adjuvant and antitumor activity. Nature New Biol., 238, 241-242.

8) Kabat, E.A.\& Mayer, M.M. (1961) Experimental Immunochemistry. 2nd ed., Charles C. Thomas Publisher, Springfield, p. 22.

9) Lederer, E. (1971) The mycobacterial cell wall. Pure appl. Chem., 25, 135-165.

10) Middlebrook, G. \& Dubos, R. (1948). Specific serum agglutination of erythrocytes sensitized with extracts of tubercle bacilli. J. exp. Med., 88, 521-528.

11) Migliore-Samour, D. \& Jollès, P. (1972) A hydrosoluble, adjuvant-active mycobacterial "Polysaccharide-peptidoglycan" preparation by a simple extraction technique of the bacterial cells (strain Peurois). FEBS Lett., 25, 301-304.

12) Migliore-Samour, D. \& Jollès, P. (1973) Hydrosoluble adjuvant-active mycobacterial fractions of low molecular weight. FEBS Lett, 35, 317-321.

13) Raffel, S. \& Cal, S. (1950) Chemical factors involved in the induction of infectious allergy. Experientia, 6, 410-419.

14) Roe, J.H. (1955) The determination of sugar in blood and spinal fluid with anthrone reagent. J. biol. Chem., 212, 335-343. 
15) Sato, H., Motomiya, M., Fukushi, K., Fujmoto, M. \& Oka, S. (1969) Wax D fraction of an unclassified mycobacterium strain. $J$. Bacteriol, 100, 469-474.

16) Schmidt, G. \& Thannhauser, S.J. (1945) A method for the determination of desoxyribonucleic acid, ribonucleic acid and phosphorproteins in animal tissues. J. biol. Chem., 161, 83-89.

17) Schneider, W.C. (1946) Phosphorous compounds in animal tissues. III. A comparison of methods for the estimation of nucleic acids. J. biol. Chem., 164, 747-751.

18) Shlomo, B.E., Constantini-Sourojon, M. \& Weiss, D.W. (1973) Potentiation and modulation of the immune response of guinea pigs to poorly immunogenic proteinhapten conjugates by pretreatment with the MER fraction of attenuated tubercle bacilli. Cellular Immunol., 7, 370-379.

19) Stewart-Tull, D.E.S. \& White, R.G. (1967) The influence of age of culture on the production of adjuvant active peptidoglycolipids by saprophytic mycobacteria. Immunology, 12, 349-359.

20) Yemm, E.W. \& Cocking, E.C. (1955) The determination of amino acids with ninhydrin. Analyst, 80, 209-213. 